\title{
MODELLING OF HEAT TRANSFER IN BUILDINGS
}

\author{
Vladimir Gerlich \\ Faculty of Applied Informatics \\ Tomas Bata University in Zlín \\ Nám. T.G. Masaryka 5555, Zlín 760 01, Czech Republic \\ E-mail: gerlich@fai.utb.cz
}

\section{KEYWORDS}

Heat transfer, building simulation, COMSOL Multiphysics, finite element method (FEM).

\begin{abstract}
The main idea of this article is taking advantage of heat energy accumulation in building walls in order to design more effective heating system. Essential article goal is to simulate thermal construction responses in dependence on changing boundary conditions. Model geometry has been developed in virtual design studio CATIA and implemented in numerical simulation software COMSOL Multiphysics, with the intention to predict environmental temperature precisely. A threedimensional finite element model of laboratory was developed with the aim of achieving detail energy transfer in the real buildings during the transient process in the walls and internal air. On the contrary, many articles utilizing water or wax energy storage to decrease heating/cooling costs this work is focused on future optimization of control strategy based on heat accumulation in walls without requirement of any additional material. In this paper simulated temperature development is analyzed in the building which is consequently verified by experimentally measured temperature data.
\end{abstract}

\section{INTRODUCTION}

Buildings are complicated structures with many bindings because of complicated geometry and variables boundary conditions. Internal air temperature is influenced by variations of outdoor conditions such as temperature, solar radiation or overcast sky. Among other things temperature in ambient areas has a minor influence to final temperature as well. Other important parameters are wall overall heat transfer coefficient, internal heat gains or sinks caused by device such as lighting, occupancy etc.

Significant tendency of decreasing energy consumption in building is evident in recent years. Many articles related to this topic is focused on energy storage using wax with low melting temperature as a medium to heat accumulation (Khudhair and Farid 2004, Heim 2010). The principle of these methods is re-using energy absorbed in melt wax material during the day. Subsequently the room air temperature is warmed up by melting heat energy when the external temperature decreases. The passive usage (not controlling) of this system leads to amplitude peak temperature differences reduction between day and night time (Heim and Clarke 2004).

Purpose of this paper is based on similar presumption but instead of special wax material required for heat accumulation, it is propose the utilization of heat accumulation in wall mass. Although the amount of energy accumulated in walls is significantly smaller in comparison to specially developed materials, the utility of this principle is much wider. The first thing to investigation is describing internal air temperature response to changing boundary parameters. Hence there was realize the primary experiment which was held last year and the additional measurement was done in this January.

Transient heat transfer is described by second order Partial Differential Equation (PDE) therefore it is necessary to solve $\mathrm{x}, \mathrm{y}, \mathrm{z}$ and time differentiations for calculating 3-dimensional transient analysis. Analytical solution of similar equation is not trivial, thus it is mostly solved with significant simplifications. Taking into account the facts mention before physical problems based on PDE are in these days calculated by the usage of computer power. A number of computer software based on different approaches can be used for numerical solution of heat transfer (HT) phenomenon. It is even possible to simulate these problems on personal computers (nowadays common 64-bit dual-core processors with several gigabytes of RAM) because of the increasing computer power.

Fundamental problems such as wall temperature stationary distribution or transient phenomenon in simple objects can be solved as 2-dimensional or even 1-dimensional tasks; contrariwise more complex problems have to be solved as 3-dimensional models. These complex models naturally need more computing power, memory and time because of the huge number of elements in which the dependent variables have to be calculated. Problem complexity can be even bigger, if it is important to couple more physics into one model such as heat and mass transfer. The number of elements can be reduced, if the specific problem is solved as symmetrical problem, but evidently this presumption is hardly fulfilled in strongly complex models.

The program used in this article for numerical calculating transient HT in buildings is called COMSOL Multiphysics (formerly FEMLAB). The main program ability is based on numerical solving of 
Table 1: Nomenclature

\begin{tabular}{|c|c|c|c|}
\hline$k$ & $\begin{array}{l}\text { Thermal } \\
\text { conductivity } \\
\left(W \cdot m^{-1} \cdot K^{-1}\right)\end{array}$ & $T$ & $\begin{array}{l}\text { Room temperature } \\
(K)\end{array}$ \\
\hline$\rho$ & $\begin{array}{l}\text { Density } \\
\left(\mathrm{kg} \cdot \mathrm{m}^{-3}\right)\end{array}$ & $T_{i n f}$ & $\begin{array}{l}\text { Outer temperature } \\
(K)\end{array}$ \\
\hline$t$ & $\begin{array}{l}\text { Time } \\
(s)\end{array}$ & $T_{a m b}$ & $\begin{array}{l}\text { Ambient } \\
\text { temperature } \\
(K)\end{array}$ \\
\hline$c_{p}$ & $\begin{array}{l}\text { Heat capacity } \\
\left(J \cdot \mathrm{kg}^{-1} \cdot K^{-1}\right)\end{array}$ & $Q$ & $\begin{array}{l}\text { Heat source } \\
(W)\end{array}$ \\
\hline$\varepsilon$ & $\begin{array}{l}\text { Emissivity } \\
(-)\end{array}$ & $q$ & $\begin{array}{l}\text { Heat flux } \\
\left(W . m^{-2}\right)\end{array}$ \\
\hline$\sigma$ & $\begin{array}{l}\text { Stefan-Boltzmann } \\
\text { constant } \\
\left(\mathrm{kg} \cdot \mathrm{s}^{-3} \cdot \mathrm{K}^{-4}\right)\end{array}$ & $h$ & $\begin{array}{l}\text { Heat transfer } \\
\text { coefficient } \\
\left(W \cdot m^{-2} \cdot K^{-1}\right)\end{array}$ \\
\hline$d$ & $\begin{array}{l}\text { Thickness } \\
(\mathrm{mm})\end{array}$ & $v$ & $\begin{array}{l}\text { Speed } \\
\left(m \cdot s^{-1}\right)\end{array}$ \\
\hline$R$ & $\begin{array}{l}\text { Thermal resistance } \\
\left(m^{2} \cdot K \cdot W^{1}\right)\end{array}$ & $\dot{Q}$ & $\begin{array}{l}\text { Heat loss } \\
(J)\end{array}$ \\
\hline
\end{tabular}

PDE by finite element method (FEM), hence its usage is wide as you can see in (Zimmerman 2006).

Nevertheless it was not used for building simulation too often. The usage of this program for similar problems can be found in (Schijndel et al. 2008; Schellen et. al. 2008). Program advantage is its ability to cooperate with MATLAB environment, which will be important for future control strategy development, examples of this linking are in (Schijndel 2008).

\section{GOVERNING MODEL EQUATION}

The HT is described by conduction and convection in walls and by conduction, convection and radiation in internal air.

\section{Domain settings}

While conduction describes the heat passage through the wall and partially the HT in internal air, convection describes the HT in internal room air. The major balance equation in domains is

$$
\nabla(-k \cdot \nabla T)+\rho \cdot c_{P} \cdot v \cdot \nabla T+\rho \cdot c_{P} \cdot \frac{\partial T}{\partial t}=Q
$$

where $k$ means heat conductivity, $T$ room temperature, $\rho$ density, $c_{p}$ heat capacity, $v$ speed, $t$ time, $Q$ heat source. The first part of this equation refers to HT by conduction, the second to convection process and the third part to heat accumulation in the mass of specific domain.

\section{Boundary settings}

There are used three types of boundary conditions. Firstly, it was used continuity boundary condition on the most of model internal boundaries. Secondly, Neumann boundary condition was calculated on external floor boundary and on boundaries with internal air

$$
q=h \cdot\left(T-T_{\mathrm{inf}}\right)
$$

where $q$ means heat flux, $h$ heat transfer coefficient (HTC), $T$ boundary temperature and $T_{\text {inf }}$ external temperature.

The values of HTC were set by CSN standard (Czech Bureau of Standards 2005). The value on the outer side of external walls was equal to $8 W \cdot m^{-2} \cdot K^{-1}$ and it had value $2.5 \mathrm{~W} \cdot \mathrm{m}^{-2} \cdot \mathrm{K}^{-1}$ on internal building walls, since it was calculated only with convection process.

On boundaries with internal air was active also second boundary equation, which describes HT by radiation

$$
q=\varepsilon \cdot \sigma \cdot\left(T_{a m b}^{4}-T^{4}\right),
$$

where $\varepsilon$ means emissivity, $\sigma$ Stefan- Boltzmann constant, $T_{a m b}$ ambient temperature, $T$ boundary temperature.

\section{PHYSICAL CASE}

\section{Geometry}

The model geometry was drawn in 3-dimensional construction design software CATIA and consequently imported to the COMSOL Multiphysics environment. Model consists of 19 domains and its visualization is shown in Figure 1. The most important model parts are (numbers in bracket refer to model parts in Figure 1): the external wall which is composed of Porotherm 400 (2), reinforced concrete (3), polystyrene insulation (4) and windows (5); the roof compile of polystyrene insulation (6) and concrete (7); internal walls consist of Porotherm 300 (1) and wooden door (8).

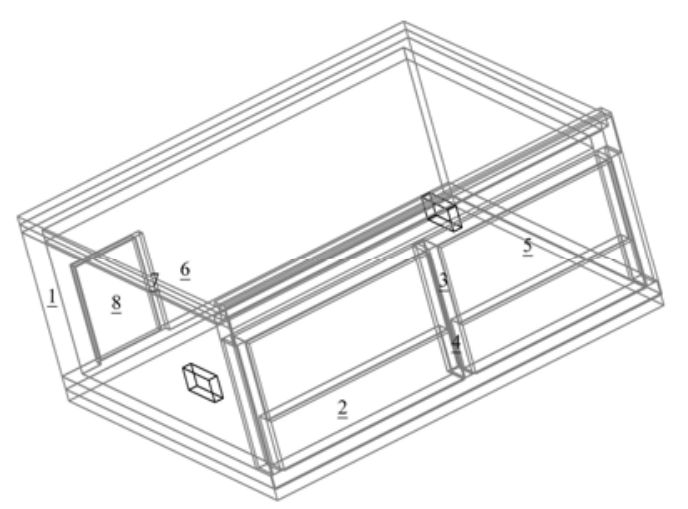

Figure 1: Geometry of Room Model

Thermal parameters of the model walls are shown in Table 2. The minimal heat resistance have internal walls; nevertheless there is a minimal heat transfer through this wall because of the minimal temperature difference. Relatively small thermal resistance of external wall is caused by large windows and small insulation thickness. 
Table 2: Thermal Construction Parameters

\begin{tabular}{|l|c|c|c|}
\hline \multicolumn{1}{|c|}{ Material } & $k$ & $d$ & $R$ \\
\hline $\begin{array}{l}\text { Porotherm } \\
300\end{array}$ & 0.250 & 300 & 1.20 \\
\hline $\begin{array}{l}\text { Porotherm } \\
400\end{array}$ & 0.150 & 400 & 2.67 \\
\hline $\begin{array}{l}\text { Polystyrene } \\
\text { (external } \\
\text { wall) }\end{array}$ & 0.034 & 50 & 1.47 \\
\hline $\begin{array}{l}\text { Polystyrene } \\
\text { (roof) }\end{array}$ & 0.034 & 280 & 8.24 \\
\hline $\begin{array}{l}\text { Concrete } \\
\text { (roof) }\end{array}$ & 1.430 & 180 & 0.13 \\
\hline $\begin{array}{l}\text { Reinforced } \\
\text { concrete }\end{array}$ & 1.430 & 55 & 0.04 \\
\hline Window & 0.024 & 12 & 0.50 \\
\hline $\begin{array}{l}\text { External } \\
\text { wall }\end{array}$ & & 1.41 \\
\hline $\begin{array}{l}\text { Internal } \\
\text { wall }\end{array}$ & & 8.36 \\
\hline Roof & & \\
\hline
\end{tabular}

\section{Experiment description}

Data used in this article were measured during the experiment in December 2010 and January 2011 in Zlin, Czech Republic. Experiment room area is $7.2 \times 8.7 \times 3 \mathrm{~m}$ and time period was almost 19 days. Temperature was measured by globe and $\mathrm{NiCr}$ thermometers in modelled room area. External weather conditions were monitored by meteorological station placed on the roof at Faculty of Applied Informatics. The room was heated up and cooled down in several cycles. Convector electric heaters were used as heat sources to control raising heat power precisely. There were used 2 electric heaters with total heat power $5 \mathrm{~kW}$. Room temperature fluctuated during experiment period in range from $14^{\circ} \mathrm{C}$ to $30^{\circ} \mathrm{C}$.

The room is located on the top floor and it has one wall and roof influenced by external weather conditions. The rest of the room walls are affected by temperatures in internal ambient areas which have their heat conditions very similar to the room temperature.

\section{Simulation description}

It was used adiabatic boundary condition on the outer part of building-internal boundaries because it was previously published in (Gerlich and Prochazka 2010), that this internal HT has minor influence on the room temperature. The room is modelled as fully tight; without ventilation or infiltration of flow rates.

The model was calculated in COMSOL Multiphysics v3.5a on computer with 2 processor - Intel Xeon (2.33 $\mathrm{GHz}, 2 \times 6 \mathrm{MB}$ cache L2, quad-core) - with 4 GB RAM. There was used free mesh with about 51000 Degrees Of Freedom (DOF) and average simulation time on this machine was about $930 \mathrm{~s}$. Linear PARDISO solver was used, since it was supposed to profit the most from the multithreading solver capability.

\section{SIMULATION OUTPUTS}

The comparison of the simulation output and the measured data is discussed now. The model will be considered as accurate enough if the average variance between simulated and measured values will be smaller than $\pm 0.5^{\circ} \mathrm{C}$.

Three-dimensional room temperature distribution (color slices) and heat flux (red cones) in the modeled room are showed in Figure 2. As it was expected, the heat flux direction implies that the majority of heat loss is through the external wall with minor roof influence.

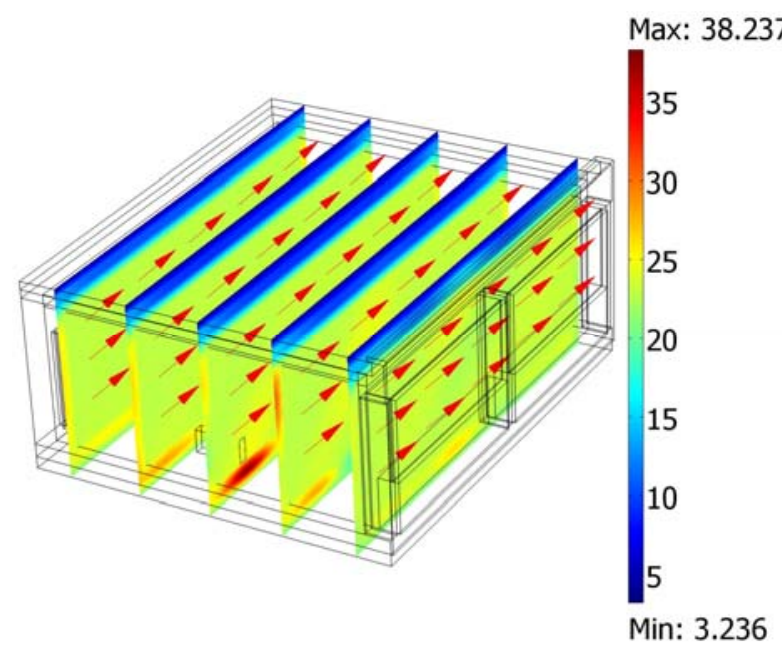

Figure 2: Temperature Room Distribution and Heat Flux

Temperature development of measured and simulated data is shown in Figure 3. The dashed-dot black line represents measured data by bulb globe thermometer and simulated values are drawn by solid blue line. There is obvious seen that simulation is very close to the experimentally measured data in which internal heat source is active. Opposite situation appears, when the room temperature decreases. In these simulation parts the value of internal HTC is too small to be able to transfer the energy to the walls, respectively to the outside environment.

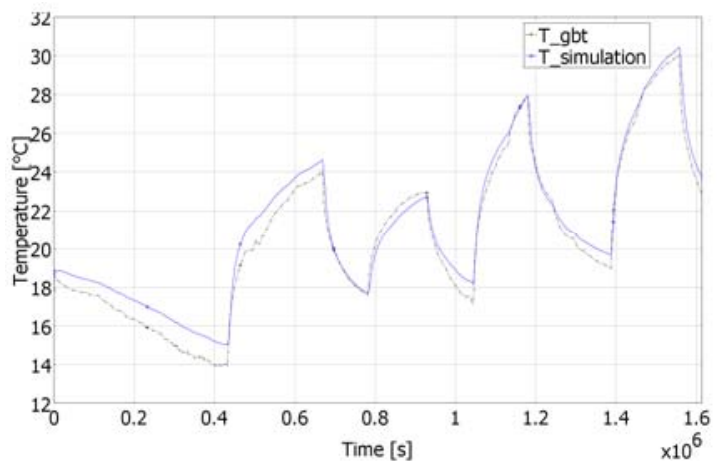

Figure 3: Simulation with Constant Value of Heat Transfer Coefficient 
There were simulated several situations with different values of HTC to solve this issue. The value of HTC remains to $2.5 \mathrm{~W} \cdot \mathrm{m}^{-2} \cdot \mathrm{K}^{-1}$ during simulation phases when the room is heated up, but there were used different HTCs when the room was cooled down. The comparison of average temperature difference vs. value of HTCs is showed in Table 3. The temperature variance decreases with rising value of HTC. This is caused by large convective part of HT due to larger temperature differences between internal air and external wall surface. Those caused large value of Nusselt, respectively Grashof number, respectively value of HTC.

Table 3: Temperature Differences for Various Value of Internal Heat Transfer Coefficient

\begin{tabular}{|c|c|c|}
\hline $\begin{array}{l}\text { HTC for cooling } \\
\text { experiment parts }\end{array}$ & $\begin{array}{l}\text { Average } \\
\text { temperature } \\
\text { difference }\end{array}$ & $\begin{array}{l}\text { Maximal } \\
\text { temperature } \\
\text { difference }\end{array}$ \\
\hline 2.5 & 0.65 & 1.91 \\
\hline 8 & 0.53 & 1.77 \\
\hline 16 & 0.45 & 1.53 \\
\hline 25 & 0.39 & 1.31 \\
\hline
\end{tabular}

Reduction of average temperature difference for almost $18 \%$ was caused by growth of HTC from $2.5 \mathrm{~W} \cdot \mathrm{m}^{-2} \cdot \mathrm{K}^{-1}$ to $8 \mathrm{~W} \cdot \mathrm{m}^{-2} \cdot \mathrm{K}^{-1}$. High simulation sensitivity of the value of HTC implies detail investigation. It was necessary to specify surfaces, which are responsible for this unexpected model behavior.

Heat fluxes presented in Figure 4 and Table 4 demonstrate that high sensitivity is caused by surfaces on external wall. The sum of the heat fluxes going through these boundaries is more than 22 times higher in comparison to sum of the rest heat fluxes. This significant difference is on the one hand caused by relatively small wall insulation and large window area in external wall and on the other hand due to notmoving air in solid soffit which improves value of roof thermal resistance.

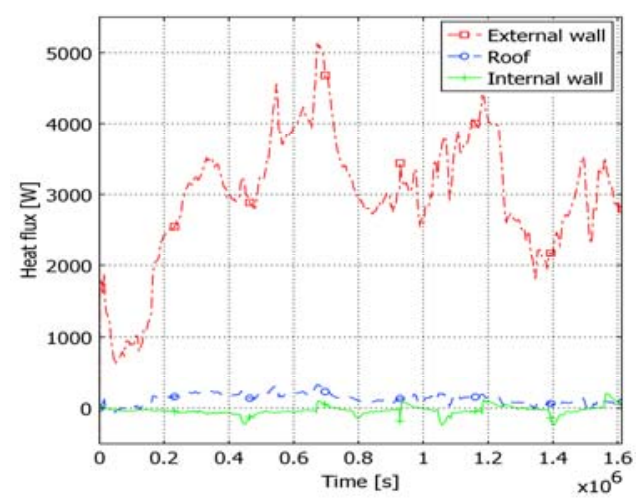

Figure 4: Heat Fluxes Comparison
Table 4: Heat Loses

\begin{tabular}{|l|c|}
\hline \multicolumn{1}{|c|}{ Boundary } & $\dot{Q}$ \\
\hline External wall & $4.81 \cdot 10^{9}$ \\
\hline Roof & $2.23 \cdot 10^{8}$ \\
\hline Internal walls & $8.67 \cdot 10^{7}$ \\
\hline
\end{tabular}

The only solution is to update value of HTC in every simulation step. It is necessary to calculate HTC on overall 11 vertical and horizontal internal wall surfaces. Instead of calculation Nusselt and Grashof number to get value of HTC, it was used internal COMSOL Multiphysics function for HTC calculation. Implementation of internal program function leads to maximized model accuracy and minimized additional calculations as well as computing time.

The simulation result with variable HTC is showed in Figure 5. Simulated and measured data are very similar in the second half of the experiment, nevertheless there is long period of inaccuracy within $400000 \mathrm{~s}$, where the difference is about $0.8^{\circ} \mathrm{C}$. It is evident from cooling phases, that simulation output has the same trend, but the cooling speed is different. This can be caused by accumulated heat in the additional room equipment such as furniture, desks and chairs. Minimal and maximal values of HTC are $2 \mathrm{~W} \cdot \mathrm{m}^{-2} \cdot \mathrm{K}^{-1}$ and $4.5 \mathrm{~W} \cdot \mathrm{m}^{-2} \cdot \mathrm{K}^{-1}$.

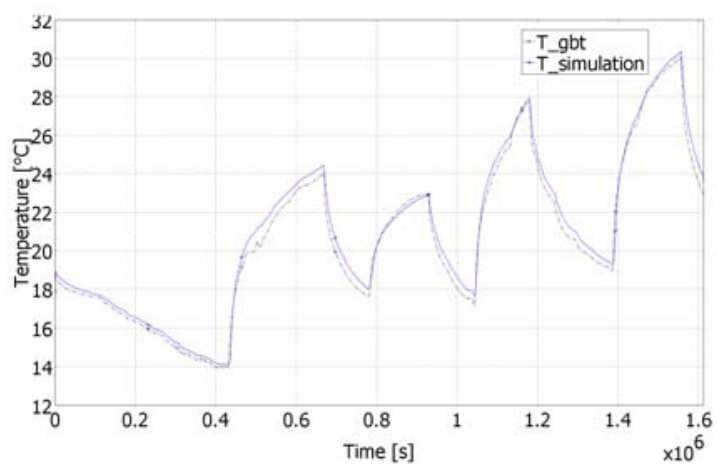

Figure 5: Simulation with Variable Value of Heat Transfer Coefficient

\section{CONCLUSION}

There was created room model, which represents building-segment based on transient HT phenomenon. It was demonstrated that it is not possible to use constant value of HTC recommended in standards for wide range of internal temperatures, because of the high model sensitivity for the value of HTC.

The simulation results with adaptive HTC value are very similar to the measured temperature development besides first experiment cycle. In general, the model accuracy is sufficient, but it is still necessary reflect limited model accuracy, which shortcoming of the model can evoke. That is because of the problematically modeled details and high model sensitivity for the value of HTC. 
Created model will be linked with MATLAB environment or other software tool for feedback control in future. COMSOL Multiphysics predestinates for this cooperation MATLAB environment, because it uses similar data structure and it is implemented COMSOL/MATLAB communication interface since COMSOL had been developed as the MATLAB toolbox FEMLAB.

\section{ACKNOWLEDGEMENTS}

The work behind the article was supported by the European Regional Development Fund under the Project CEBIA-Tech No. CZ.1.05/2.1.00/03.0089 and by the by the internal grant agency of Tomas Bata University in Zlin with NO. IGA/44/FAI/10/D.

\section{REFERENCES}

Czech Bureau of Standards. 2005. Thermal performance of buildings - Calculation of internal temperatures of a room in summer without mechanical cooling - Simplified methods. Prague, (Aug).

Gerlich, V. and M. Prochazka. 2010. "Influence on room temperature by heat transfer from surrounding areas". In. Proceedings of the International Conference MMK 2010. (Hradec Kralove, Dec.6-10). 85-91.

Heim D. and J. A. Clarke. 2004. "Numerical modelling and thermal simulation of PCM-gypsum composites with ESP-r". Energy and Buildings, No. 36, 795-805.

Heim D. 2010. "Isothermal storage of solar energy in building construction". Renewable Energy, No. 35, 788-796.

Khudhair A. M. and M. M. Farid. 2004. "A review on energy conservation in building applications with thermal storage by latent heat using phase change materials". Energy Conversion and Management, No. 45, 263-275.

Schellen, H.L.; A. W. M. van Schijndel; and P. M. Briggen. 2008. "The use of COMSOL for Building Constructions Engineering regarding Heat and Moisture Transport". In Proceedings of the COMSOL Conference 2008 (Hannover, Nov.4-6).

Schijndel A. W. M. van; H.L. Schellen; J.L. Wijffelaars; and K. van Zundert. 2008. "Application of an integrated indoor climate, HVAC and showcase". Energy and Buildings.No. 40, 647-653.

Schijndel J. van. 2008. Integrated Modeling using MatLab, Simulink and COMSOL: with heat, air and moisture applications for building physics and systems. Saarbrucken: VDM Verlag Dr. Muller Aktiengesellschaft \& Co. KG,. 197 p. ISBN 978-3-639-10669-5.

Zimmerman W. B J. 2006. Multiphysics Modelling with Finite Element Methods. Ardéshir Guran. 1st edition. Singapore : World Scientific Publishing Co. Pte. Ltd., 2006. 422 p. ISBN 10 981-256-843-3.

\section{AUTHOR BIOGRAPHIES}

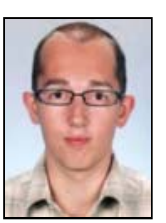

VLADIMIR GERLICH was born in Uherske Hradiste, Czech Republic and went to the Tomas Bata University in Zlin, where he studied automatic control and obtained his degree in 2008. He is now studying doctoral program on TBU in Zlin in the field of heat transfer in buildings. His e-mail address is : gerlich@fai.utb.cz. 